\title{
The Challenge of Performing Aerobic Exercise in Tropical Environments: Applied Knowledge and Perspectives
}

\author{
Olivier Hue
}

The tropical climate is unique in that the seasons are dominated by the movement of the tropical rain belt, resulting in dry and wet seasons rather than the four-season pattern of changes in temperature and day length seen in other parts of the world. More than $33 \%$ of the world population lives in the humid tropics, which are characterized by consistently high monthly temperatures and rainfall that exceeds evapotranspiration for most days of the year. Both the 2014 Football World Cup (in Brazil) and the 2016 Olympic Games (in Rio de Janeiro) will take place in this climate. This review focuses on the effects of the tropical environment on human exercise performance, with a special emphasis on prolonged aerobic exercise, such as swimming, cycling, and running. Some of the data were collected in Guadeloupe, the French West Indies Island where all the French teams will be training for the 2016 Olympic Games. We will first fully define the tropical climate and its effects on performance in these sports. Then we will discuss the types of adaptation that help to enhance performance in this climate, as well as the issues concerning the prescription of adequate training loads. We will conclude with some perspectives for future research.

Keywords: swimming, cycling, running, triathlon, acclimation

\section{The Specificity of Hot and Humid Environment}

Humid tropics are characterized by consistently high monthly temperatures, often exceeding $18^{\circ} \mathrm{C}$ throughout the year, and rainfall that exceeds evapotranspiration for at least 270 days per year. ${ }^{1}$ The detrimental effect of high environmental temperature on aerobic performance has been well documented, and it is widely acknowledged that exercise-heat acclimation involves a complex set of adaptations that serve to reduce physiological strain and improve the ability to exercise in the hot environment. However, although considerable information has been gathered on the physiological adaptation to hot/dry climates (4027 hits on PubMed for "aerobic exercise in the heat"), data on acclimation to hot/humid climates are more limited (fewer than 100 hits on PubMed for "aerobic exercise in hot-humid/tropical environment/ climate"). The earlier studies cited by Pandolf ${ }^{2}$ demonstrated that nearly complete

Olivier Hue is with Laboratoire ACTES, UFR-STAPS, Université des Antilles et de la Guyane, Guadeloupe, France. 
heat acclimation for both hot/dry and hot/humid environments occurs after 7 to $10 \mathrm{~d}$ of exposure. In agreement with these earlier studies, Nielsen ${ }^{3}$ showed that physiological adaptations were similar in humid and dry heat when subjects exercised daily for $8-12$ consecutive days. Furthermore, $66 \%$ to $75 \%$ of the physiological adjustments were seen in 4 to $6 \mathrm{~d},{ }^{2}$ and it has been suggested that high levels of aerobic capacity aid the individual to acclimate. ${ }^{4}$ The recommendations were thus that competitive athletes expecting to participate in events involving heat stress should acclimate/ train in the heat for at least $5 \mathrm{~d}$ beforehand to help maximize performance. ${ }^{4}$

The above results are in contrast to studies specifically comparing the effects of acclimation to a hot/dry climate to those created by a vapor barrier suit (NBC suit) that creates a hot/humid microclimate regardless of the ambient conditions ${ }^{5}$ and the well-known theoretical study by Nielsen ${ }^{6}$ for the 1996 Olympics in Atlanta. The first showed that at the same exercise intensity, the strain was higher (rectal temperature and heart rate were higher by about $1{ }^{\circ} \mathrm{C}$ and 30 beats. $\mathrm{min}^{-1}$, respectively) when subjects were tested with the suit after $10 \mathrm{~d}$ of acclimation, thus clearly demonstrating the difference between hot/dry and hot/humid acclimation conditions. The second study demonstrated the very negative impact of hot-wet conditions ${ }^{6}$ on marathon performance, whatever the athlete level or acclimation.

To date, unfortunately, the data on hot/humid conditions, in which the high required evaporative cooling exceeds the evaporative capacity of the environment ${ }^{7}$ - thereby inducing an irreversible decrease in performance ${ }^{6}$ - have only been extrapolated using laboratory artifacts (ie, tropical climate created in laboratories) or mathematical calculations. Studies exploring the physiological responses elicited by a natural hot/humid climate or during outdoor testing are very few.

The specificity of the tropical (ie, hot/humid) environment is the high degree of humidity that does not permit adequate evaporation. Thus, when the environmental evaporative capacity is limited, adherence to the strategy used in a hot/dry climate (ie, reducing heat storage by increasing the sweating rate) creates a physiological disadvantage ${ }^{7}$ that results in severe dehydration. The only way to achieve a match between heat gain and heat dissipation during outdoor exercise is by reducing the metabolic heat production, and thus the intensity.

Guadeloupe is a good example of tropical environment: this island is located in the Caribbean Sea in the northern hemisphere $\left(16^{\circ} \mathrm{N}, 60^{\circ} \mathrm{W}\right)$. It has a mean temperature of $25-26^{\circ} \mathrm{C}$ and a mean relative humidity $(\mathrm{RH})$ of $80-82 \%$. The temperature is relatively constant, with about a $3.2^{\circ} \mathrm{C}$ difference between the hottest months $\left(26.7^{\circ} \mathrm{C}\right.$ in June, July, and August) and the coldest $\left(23.5^{\circ} \mathrm{C}\right.$ in January and February). The humidity, on the other hand, is quite variable, with a "humid" season (June to November, always $>85 \% \mathrm{RH}$ ) and a "dry" one (December to May, a mean of 75\% RH). Guadeloupe is where all French teams will prepare for the 2016 Olympic Games.

\section{Aerobic Exercise in Hot and Humid Environment}

\section{Swimming}

A particularly interesting question concerns the extent to which swimming affects the process of acclimating to a tropical climate. The thermal balance of swimmers is well known to be regularly challenged because of the high heat transfer coefficient of water. ${ }^{8}$ Although most studies have reported the effect of cold water on thermoregulation, swimming in high temperature increases heart rate in relation 
with hyperthermia and increases skin circulation and esophageal temperature to the same extent as running in a hot environment. ${ }^{9}$ These authors noted an increase of 8 beats. $\mathrm{min}^{-1}$ in heart rate from $26^{\circ} \mathrm{C}$ water to $34^{\circ} \mathrm{C}$ water during a $20 \mathrm{~min}$ submaximal swimming exercise (approximately $50 \%$ of $\mathrm{VO}_{2} \mathrm{max}$ ), certainly in relation with the skin temperature increase. Swimming thus induces high thermoregulatory stress in hot/humid climate. We recently ${ }^{10}$ demonstrated that the aerobic performance of competitive swimmers (measured over an $800 \mathrm{~m}$ front crawl performed with and without a swim cap) was affected by the combination of the high convection and conduction capacity of water and the use of the silicone swim cap usually worn for training and competition (Figure 1). These swimmers swam in an outdoor $33^{\circ} \mathrm{C}$
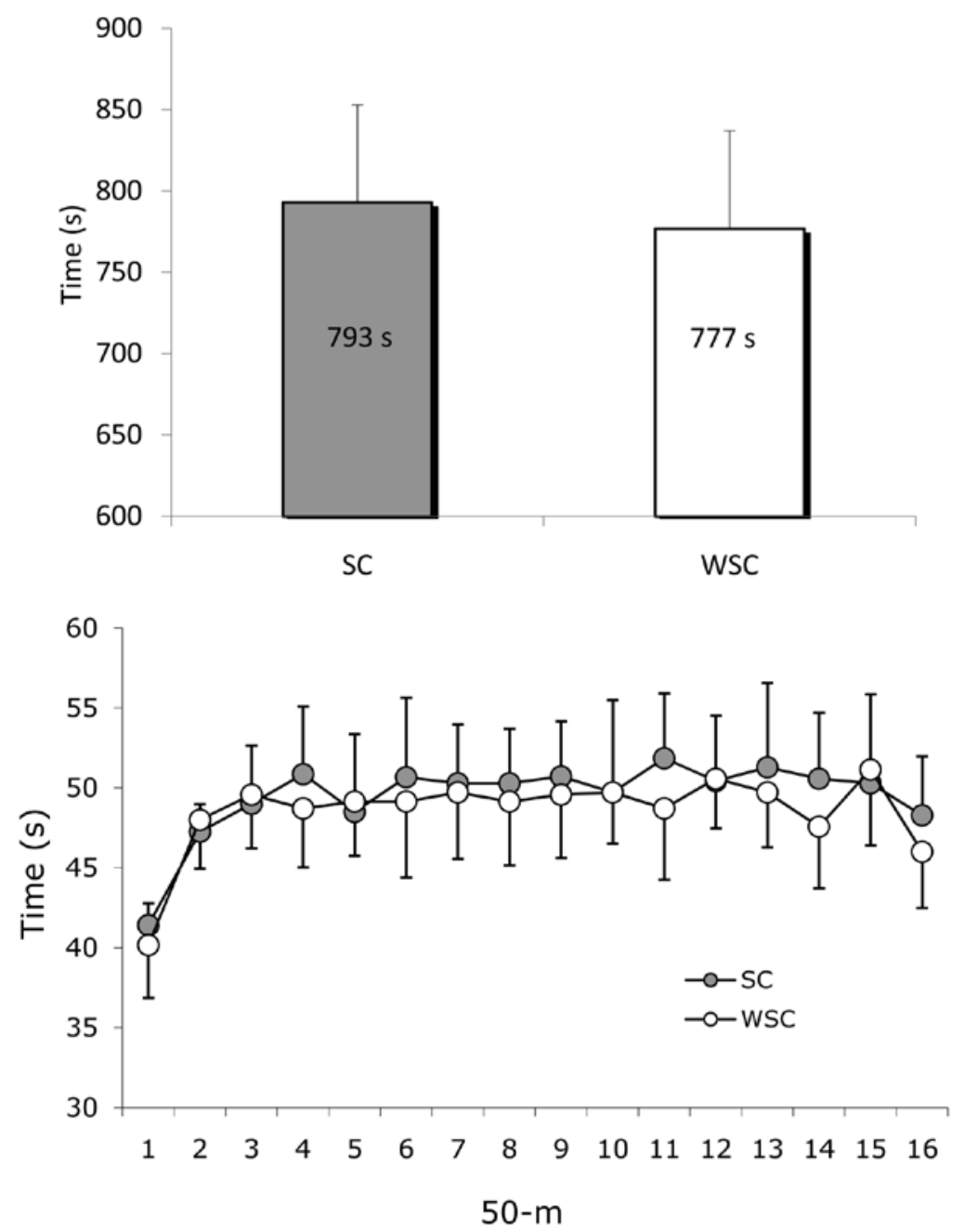

Figure 1 - Performance of acclimated swimmers during a $800 \mathrm{~m}$ front crawl event, with (SC) and without swim cap (WSC). Top: mean \pm SD time. Bottom: mean time noted each $50 \mathrm{~m}$. 
swimming pool in hot/humid climate (air temperature: $29.2^{\circ} \mathrm{C}$; hygrometry: $74 \%$ ), and the results indicated that swimming with a silicone cap on the head could be a stress for the central command of sudation, ie, the hypothalamus. Thermoregulation during training sessions may decrease training intensities and thereby have a negative effect on future performance in competition. We therefore recommended that competitive swimmers and their coaches envisage removing the silicone swim cap during training sessions and competitions of $800 \mathrm{~m}$ or more in tropical environmental conditions.

\section{Triathlon Swimming}

Several studies have investigated the effect of a wet suit in different water temperatures and its effect on overall triathlon performance. Kerr et $\mathrm{al}^{11}$ demonstrated that wearing a wet suit while swimming did not affect the performance of subsequent cycling and running stages in a triathlon performed in $32^{\circ} \mathrm{C}$ and $65 \% \mathrm{RH}$. They found no significant increase in core temperature with a wet suit (versus a swimsuit) in a $30 \mathrm{~min}$ swim at $25.4^{\circ} \mathrm{C}$, and thus no incidence of the swimming event on the subsequent cycling and running in tropical climate. As cited by the authors themselves, "swimming with wet suit in relatively warm water" (ie, $26^{\circ} \mathrm{C}$ in this study) "does not impede performance during subsequent stages ..." (ie, cycling and then running in triathlon); however, the water temperature noted in tropical areas is somewhat higher and can reach $33^{\circ} \mathrm{C}$. The same results were recently obtained by Peeling and Landers. ${ }^{12}$ The triathletes used a speedsuit to swim in a $27.9^{\circ} \mathrm{C}$ water temperature ("a relatively warm temperature"), which had no effect on subsequent cycling and running stages performed at $30^{\circ} \mathrm{C}$ and $60 \% \mathrm{RH}$.

\section{Cycling}

It has been demonstrated that prolonged submaximal cycling performance is greatly decreased by dehydration and/or hyperthermia in the laboratory, ${ }^{13}$ in which convective and evaporative cooling is likely to be less than that encountered in outdoor competition. During a 90 min ride performed in a climatic chamber with airflow provided by a fan placed in front of the bike at the level of the subject's head and chest $\left(5.7 \mathrm{~m} \cdot \mathrm{s}^{-1}\right.$; ie, $\left.20.5 \mathrm{~km} \cdot \mathrm{h}^{-1}\right)$, Sheffield-Moore et $\mathrm{al}^{14}$ demonstrated higher core temperature in hot/humid $\left(35^{\circ} \mathrm{C}, 70 \% \mathrm{RH}\right)$ than in hot/dry $\left(35^{\circ} \mathrm{C}, 20 \% \mathrm{RH}\right)$ laboratory conditions from 60 to $90 \mathrm{~min}$, with a significantly greater increase (+6 beats. $\mathrm{min}^{-1}$ ) in heart rate in the humid treatment from 15 to $90 \mathrm{~min}$.

However, elite cyclists ride at speeds ranging from 20 to $50 \mathrm{~km} \cdot \mathrm{h}^{-1}$, which generates an equivalent facing windspeed that normally allows for enough thermoregulation. Recently, Saunders et a ${ }^{15}$ compared cycling at different air velocities in the laboratory in warm and humid conditions and demonstrated that when air velocity is $33 \mathrm{~km} \cdot \mathrm{h}^{-1}$ or higher, the evaporative capacity of the environment increases proportionately so that excess heat is reduced. Higher rates of fluid ingestion thus have no further influence on heat storage, body temperature, sweat rate, heart rate, or rating of perceived exertion.

These conclusions were corroborated by Hue et $\mathrm{al}^{16}$ during a field study. These authors demonstrated that the physiological parameters (ie, mean HR, lactate response) and performances (ie, average speed) during a major sporting event in tropical conditions (ie, Tour de Guadeloupe, a $9 \mathrm{~d}$ cycling race; mean conditions: 
$31^{\circ} \mathrm{C}$ and $76 \% \mathrm{RH}$ ) did not differ from those recorded during similar events performed in neutral conditions (ie, Tour de France, Vuelta a España; Lucía et $\mathrm{al}^{17}$ ). These findings highlight the positive effects of high convection (linked to high cycling velocity) on the efficiency of the evapotranspiration processes in tropical climate.

Even wearing a helmet while riding in a hot/dry or hot/humid environment does not cause hyperthermia in competitive cyclists: Sheffield-Moore et a ${ }^{14}$ demonstrated no significant difference in hot/humid climate $\left(35^{\circ} \mathrm{C}, 70 \% \mathrm{RH}\right)$ with or without a helmet during a 90 -min ride performed in a climatic chamber.

\section{Running}

Because running speeds are lower than cycling speeds, the effect of air convection is of less importance. When running performance was analyzed in poor air velocity conditions, hot/humid climate was shown to have a strong effect on performance. ${ }^{18}$ However, the lack of adequate airflow in the laboratory substantially reduces the combined heat transfer coefficient and the physiological strain may be overestimated. Heat production in running has been described as depending (ie, increasing with) on the athlete's body mass and speed, ${ }^{6}$ and in prolonged running events such as the marathon, thermoregulation can be a problem. ${ }^{18}$ Ely et al ${ }^{19}$ recently studied the impact of weather on marathon-running performance and demonstrated that marathon performance progressively slowed as the wet bulb globe temperature increased from $5^{\circ} \mathrm{C}$ to $25^{\circ} \mathrm{C}$. This was observed in both men and women, but the effect was more negative for slower populations. As noted above, body mass is negatively associated with running performance in hot/humid conditions. Because heat production in running depends on body mass and especially muscle mass (ie, muscle producing most of the heat during exercise) and heat loss depends on surface area, an athlete's body mass has an approximately twofold greater effect on heat production than on heat dissipation. ${ }^{20}$ Running speed also increases heat production more than heat dissipation, and while heat production depends on absolute running speed, heat exchange by convection and evaporation is determined by the square root of the velocity airflow over the skin. ${ }^{20}$ This implies that at $35^{\circ} \mathrm{C}$ and $60 \% \mathrm{RH}$, the running speed at which a $45 \mathrm{~kg}$ athlete maintains thermal balance is almost $7 \mathrm{~km} \cdot \mathrm{h}^{-1}$ faster than that of a $75 \mathrm{~kg}$ athlete. ${ }^{20}$ In fact, in hot/humid climates with heat dissipation mechanisms at their limits, runners with lower body mass have a distinct thermal advantage: lighter runners produce and store less heat at the same running speed; hence, they can run faster or further before reaching a limiting rectal temperature. ${ }^{21}$

\section{Adaptation to Hot and Humid Climate When Exercising}

\section{Acclimated Versus Unacclimated Individuals}

Heat acclimation (HA) refers to an increase in heat tolerance while working or exercising under stress conditions. ${ }^{3,22}$ Acclimation processes are enhanced in well-trained subjects, especially in those with high $\mathrm{VO}_{2} \max$, and are facilitated by continual daily 100 min exercise. ${ }^{2}$ The physiological adaptations of HA include increased cardiac output, stroke volume, sweat rate, and blood plasma volume; 
decreased heart rate, core temperature, and mean skin temperature at rest; decreased rectal temperature at rest; and increased oxygen consumption at a given work rate along with earlier sweating during exercise. ${ }^{22}$ Although some of the processes have been demonstrated to also occur within 8 and $14 \mathrm{~d}$ in tropical climate (Figure 2), ${ }^{23,24}$ the full acclimation expected by athletes (ie, to be able to reproduce the same performance in a stressful climate after acclimation as in neutral environment) has failed to become a reality.

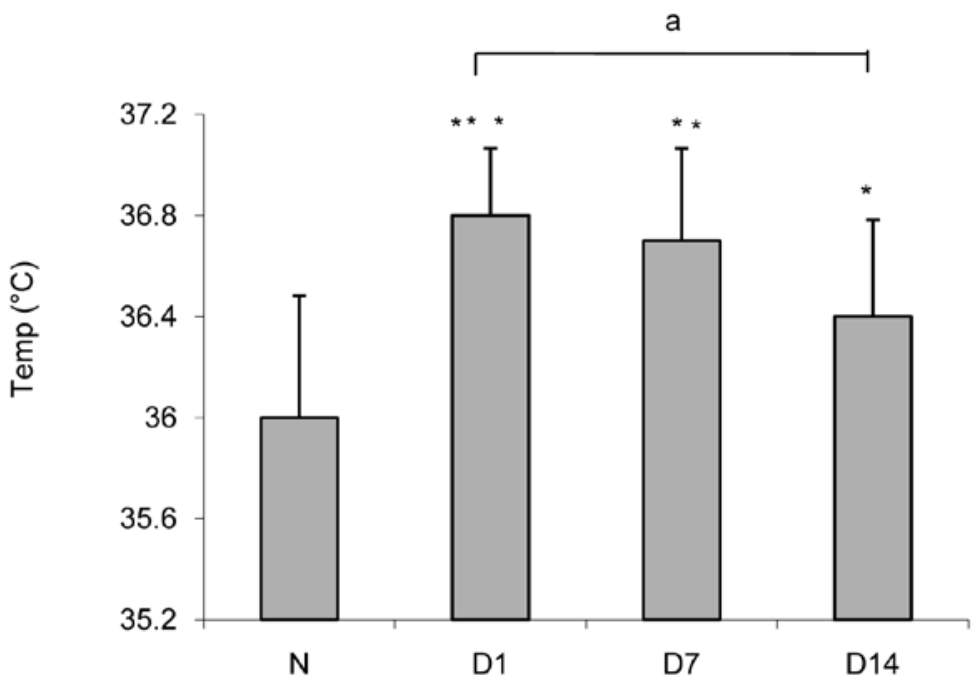

Figure 2-Morning rectal temperature obtained in neutral environment $(\mathrm{N})$, and 2, 8, and 14 $\mathrm{d}$ after arrival in tropical environment. (*Different from neutral environment, a: time effect).

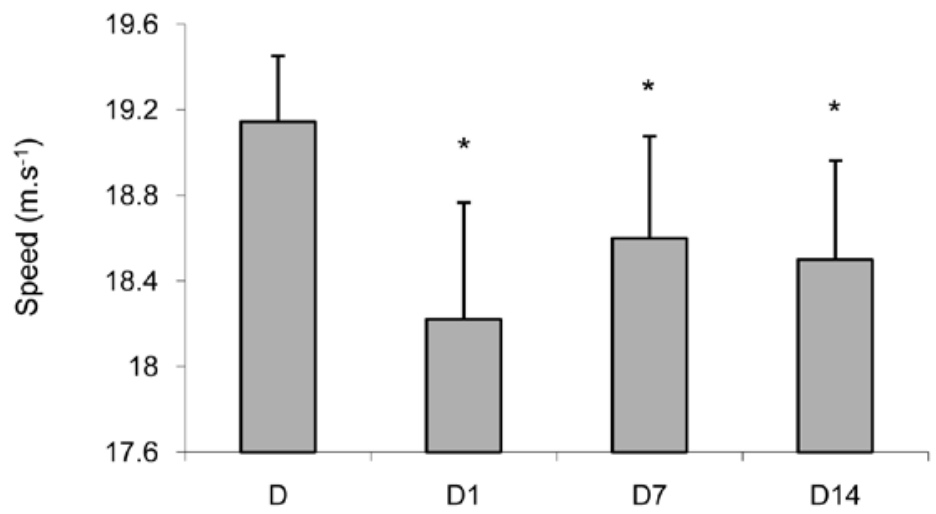

Figure 3 - The maximal running speed in high-level triathletes during an incremental running test was significantly lower $2 \mathrm{~d}$ after arrival in tropical climate $\left(32.9^{\circ} \mathrm{C}, 78 \% \mathrm{RH}\right.$ for D2, D8, and D14) and did not reach the maximal speed in neutral environment $\left(\mathrm{N} ; 14^{\circ} \mathrm{C}\right.$, $45 \% \mathrm{RH})$ at either day 8 or day $14 .^{24}$ 
We demonstrated significantly lower performance during a maximal incremental outdoor running test in high-level triathletes after 8 and $14 \mathrm{~d}$ of acclimation in tropical climate (Figure 3), ${ }^{23,24}$ putting into evidence the difficulty of fully acclimating to tropical environment. The subjects of the studies were well-trained, had high $\mathrm{VO}_{2} \max$, and trained for more than $2 \mathrm{~h}$ per day in the tropical climate (ie, they trained for $4 \mathrm{~h} \cdot \mathrm{day}^{-1}$, the same training schedule as in neutral climate), which are the three characteristics reported to facilitate the acclimation process. ${ }^{2}$

Some authors have demonstrated that acclimated individuals (ie, people native to or having lived in tropical climate for at least $2 y)^{25}$ show heat tolerance with suppressed sweating, ${ }^{25}$ which provides the advantage of preserving body fluid and osmoregulation in order to better thermoregulate. However, this adaptation was demonstrated to be insufficient when exercising, at least during prolonged exercise at high intensity. Saat et $\mathrm{al}^{26}$ demonstrated that natives to tropical climate, as well as those who have lived in tropical climate for at least $2 \mathrm{y},{ }^{25}$ had lower sudation and higher skin temperature (ie, resulting in higher vapor pressure at the skin surface, thus improved evaporation) and rectal temperature at $40 \% \mathrm{VO}_{2} \mathrm{max}$, but Voltaire et $\mathrm{al}^{27}$ demonstrated that natives to tropical climate had significantly lower 1 - $\mathrm{h}$ cycling performance at $80 \%$ HRmax in tropical than in neutral climate (Figure 4).

Very recently, Lorenzo et $\mathrm{al}^{28}$ demonstrated that compared with $10 \mathrm{~d}$ of daily training in cold climate $\left(13^{\circ} \mathrm{C}\right), 10 \mathrm{~d}$ of daily training in hot/dry climate $\left(40^{\circ} \mathrm{C}\right)$ increased aerobic performance in temperate conditions and provided some expected benefits (ie, less of a decrease in performance in hot conditions than in temperate ones). This study implies that regularly training in hot conditions for athletes living in temperate climate would help to prevent a substantial decline in performance when competitions are held in hot climate.

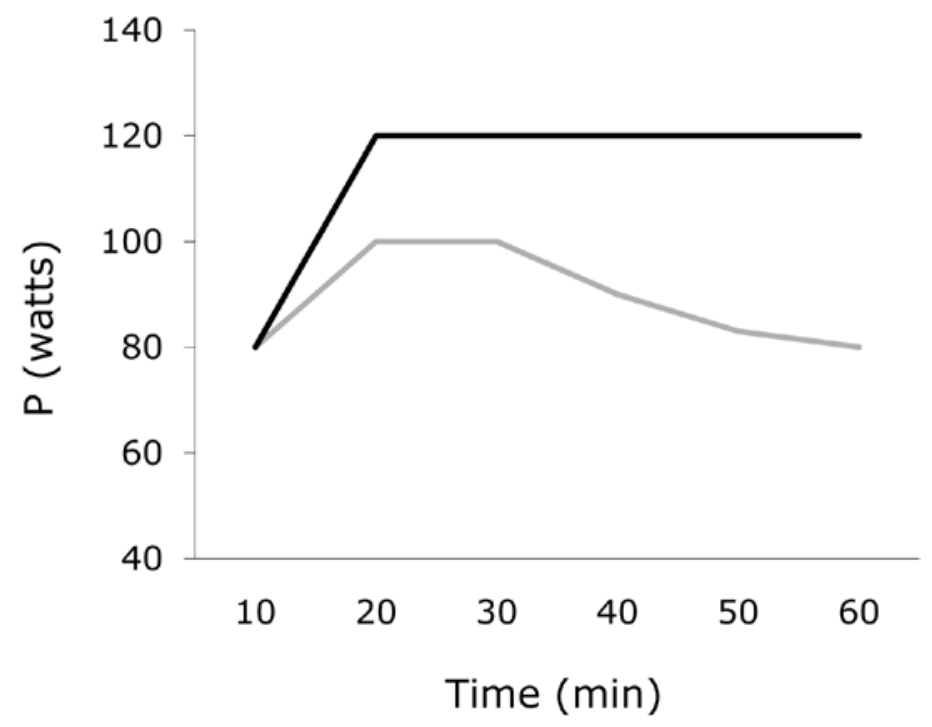

Figure 4 - Power output (P) during 60 min of cycling in tropical (gray line) versus neutral (black line; $19^{\circ} \mathrm{C}, 52 \% \mathrm{RH}$ ) climate in natives to tropical climate (ie, the intensity was maintained at $\left.80 \% \mathrm{HRmax} ; 33^{\circ} \mathrm{C}, 75 \% \mathrm{RH}\right){ }^{27}$ 


\section{Sex and/or Anthropometric Effects}

The advantages of smaller body mass when distance running in warm and humid conditions have been demonstrated;20,21 see the "Running" subsection, above. The impact of the body surface area/mass ratio suggests that women are in a better situation to thermoregulate in hot/humid climate. Normally, men display better thermoregulation capacity due to a faster sweat rate and a larger body mass, enabling greater heat accumulation. In hot/humid climate, however, they are unable to benefit from their higher sweat rate because of the reduced evaporative capacity of humid air. In fact, their greater sweat loss induces dehydration and a consequent loss in exercise performance. The lower running performance of women than men in hot/ humid climate has been demonstrated to be due only to their lower lean body mass (ie, for similar body mass) and not to lower thermoregulation, ${ }^{29}$ both in luteal and follicular phases ${ }^{29}$ and at least in trained women. ${ }^{30}$

\section{Training Prescription in Hot and Humid Environment}

\section{Testing in a Climatized Laboratory to Prepare for Competitions in Hot and Humid Conditions}

The prescription of training loads for endurance sports is often based on heart rate (HR) data, as HR is an indicator of exercise intensity up to levels close to maximal oxygen uptake $\left(\mathrm{VO}_{2} \max \right)$. Target $\mathrm{HR}$ recommendations are often based on the results of laboratory exercise tests performed in climatized rooms, during which several of the parameters encountered in performance assessment are measured. The first (VT) and second (RCT) ventilatory thresholds can be determined during progressive exercise testing, and both are important predictors of performance in endurance exercise. Thus, determination of the specific HR associated with these two thresholds is of great use in prescribing adequate training loads based on HR data.

The effect of heat exposure on $\mathrm{VO}_{2}$ max has been extensively studied, although these results have been contradictory. Maximum oxygen uptake has been shown to be reduced, unaltered, or increased when subjects exercise in heat, whether or not they are dehydrated. ${ }^{31}$ During exercise in a hot/humid environment, both dehydration and hyperthermia occur rapidly, affecting the cardiovascular system. Moreover, the fluid loss by sweating induces an HR drift ${ }^{31}$ that could disturb the HR-VT/RCT relationships. In addition, hyperthermia has a direct effect on ventilation, related to temperature-mediated stimulation of the thermal receptors. ${ }^{32} \mathrm{~A}$ direct effect of increased core temperature has also been hypothesized to cause a change in the equilibrium constants of the $\mathrm{CO}_{2}$ buffer system, resulting in a diminished capacity to buffer $\mathrm{CO}_{2}$ by body fluids. ${ }^{32}$ Therefore, testing athletes in a climatized laboratory could yield data that cannot be generalized to training in a tropical environment. We recently conducted a study to determine whether VT and RCT are similar in tropical and neutral conditions in acclimated elite cyclists performing a maximal cycling test. We observed that hyperthermia occurred in the tropical conditions of Guadeloupe $\left(25.8^{\circ} \mathrm{C}, 63.7 \% \mathrm{RH}\right)$, and this was indicated by the greater ventilatory cost of cycling and a decrease in maximal power output. ${ }^{33}$ 
However, we demonstrated no significant difference between the two conditions regarding the parameters usually used to prescribe training loads, which suggested that testing cyclists in a climatized laboratory will yield good information for training prescription in tropical climate.

We obtained similar data during an incremental outdoor running test performed in tropical climate: a decrease in maximal aerobic velocity. ${ }^{24}$ However, because the test was performed outdoors we had no information on the ventilatory threshold. Further studies are thus needed to explore how closely climatized test results correspond to running performance in tropical climate.

\section{Time of Day to Train and Perform}

The effect of time of day on performance in tropical climate has been extensively studied for anaerobic exercise, ${ }^{34}$ but there are few data on the time-of-day effect on aerobic performance. Recently, Hobson et $\mathrm{al}^{35}$ demonstrated significantly longer cycling exercise in a hot/humid climate $\left(35^{\circ} \mathrm{C}, 60 \% \mathrm{RH}\right)$ in the morning $(06: 45)$ than in the early evening (18:45), in relation with lower skin temperature and heart rate. However, the subjects of the study were living in neutral environment and thus were not affected throughout the day and night by tropical climate. The subjects presented lower HR and lower core temperature in the morning than in the evening, which certainly delayed the rise in core temperature to the critical point that stops exercise (the same in the study at the end of exercise for the morning and evening tests). This difference in rectal temperature between morning and evening might not occur in individuals living in tropical environment or the difference might be smaller, ${ }^{34}$ in which case the time to exhaustion in the morning would not be longer. Moreover, the core temperature of individuals living in a tropical area, with little difference in the night/day temperature or the morning/afternoon temperature, might not be the same as that of individuals living in neutral environment. Last, the effect of sleeping in a climatized room has to be taken into account in these studies if they were conducted in tropical environment.

\section{Optimization of Performance in Hot and Humid Environment}

Because the hot/humid environment decreases performance (if no convection is available), athletes who plan to compete in this climate need to be well advised. First, well-trained subjects acclimate better than less trained subjects, as high aerobic capacities are thought to be involved in the acclimation process. Second, even $14 \mathrm{~d}$ is not sufficient to completely acclimate (ie, to reach the same performance level as in neutral climate), as demonstrated by Voltaire et al, ${ }^{24}$ who showed that the acclimation process emerged at $8 \mathrm{~d}$ and ended at $14 \mathrm{~d}$ (ie, physiological adaptations). Third, $2 \mathrm{~h}$ of daily training facilitates the acclimation process ${ }^{2}$ and, fourth, hyperthermia and dehydration are worse than hyperthermia alone. ${ }^{36}$ Thus, a well-trained athlete with high aerobic capacity, arriving in the hot/humid climate at least $10 \mathrm{~d}$ before the sporting event and willing to hydrate as recommended, ${ }^{36}$ could certainly perform optimally, despite the insurmountable deleterious effects of the hot and humid climate on prolonged sporting performance. 


\section{Perspectives}

\section{Training in Tropical Climate to Increase Performance in Neutral Climate}

Training in tropical climate in order to optimize performance in neutral climate or to minimize the effects of tropical climate seems to be an interesting perspective. In fact, tropical training might be as interesting as training at altitude. Hypervolemia is one of the most important (and performance-related) adaptations that occurs during aerobic exercise ${ }^{37}$ and hyperthermia the most important factor of environmental stress. ${ }^{38}$ We recently demonstrated the positive effect (ie, a $10 \%$ increase in performance in $400 \mathrm{~m}$ front crawl swimming) of $8 \mathrm{~d}$ of training in tropical climate for national- to international-level swimmers. ${ }^{39}$ The same observations were recently made by Lorenzo et $\mathrm{al}^{28}$ in the laboratory. However, similarly to the observations for altitude training, the decay of acclimation to tropical climate is variable and occurs between $1 \mathrm{wk}$ and $1 \mathrm{mo}^{2}$ This thus should be carefully studied in other sports.

\section{Living in Tropical Climate: A Perspective for Athletic Progress?}

Few data are available on the additional loads of training and living in tropical climate. Normally, the training load (in terms of training intensity and quantity) is established to bring about progress in performance.

We demonstrated a HR 30 beats $\cdot \mathrm{min}^{-1}$ higher for the same power output during $1 \mathrm{~h}$ of cycling ${ }^{27}$ performed at approximately 50-60\% maximal power output in tropical versus neutral climate. In another study, we demonstrated that $14 \mathrm{~d}$ of acclimation induced hypervolemia, which resulted in significantly lower HR in tropical than neutral environment for the same speed. ${ }^{24}$ However, this was only noted below the RCT; above the RCT, the costs of the tropical environment and exercise had a combined impact that impeded the thermoregulation process from preventing hyperthermia. Undoubtedly, training for long hours (as do cyclists, triathletes, swimmers, and runners) in tropical climate imposes an additional load that has to be taken into account to prevent overtraining, and even to simply ensure the adequate recovery time needed for athletic progress. Although Lorenzo et $\mathrm{al}^{28}$ recently suggested that training in hot climate could be used to further stimulate adaptations and thus increase aerobic performance, it must be noted that their "additional" load lasted only $10 \mathrm{~d}$. The impact of living in a tropical climate is even stronger: the long-term physiological adaptations of living in tropical climate are well known (see herein the subsection "Acclimated Versus Unacclimated Individuals"). However, the effects of these adaptations on long-term fatigue processes are not well known and need to be explored because they may play a role in exercise adaptation and recovery in tropical climate. The circadian rhythms observed in some tropical areas may also play a role in exercise adaptation to tropical climate. The night-day rhythm in tropical areas is regular (approx. $12 \mathrm{~h}$ day [06:00 to 18:00] and $12 \mathrm{~h}$ night [18:00-06:00]) all year long, with little variation in temperature. The seasonality of the circadian rhythm in neutral climate has been confirmed by higher rectal temperature in summer than in winter and an earlier shift in rectal temperature in summer than in winter. ${ }^{40}$ Therefore, the diurnal variation in ther- 
moregulatory responses is also affected by seasonal changes in body-temperature circadian rhythm. ${ }^{41}$ The thermoregulatory responses to heat stress are thus seasonally changed in humans living in a neutral environment (or an environment with summer-winter seasons), but this would be different in individuals living in tropical areas. The specific adaptations induced by exercise in tropical climate should thus also be explored in people living in tropical areas because long-term physiological responses may be dependent on long-term heat stress.

\section{References}

1. Salati E, Lovejoy TE, Vose PB. Precipitation and water recycling in tropical forests. Environmentalist. 1983;3:67-72.

2. Pandolf KB. Time course of heat acclimation and its decay. Int J Sports Med. 1998;19(Suppl 2):S157-S160.

3. Nielsen B. Heat stress and acclimation. Ergonomics. 1994;37:49-58.

4. Pandolf KB, Sawka MN, Gonzales RR. Benchmark Press, Inc. Indianapolis: Human Performance Physiology And Environmental Medicine At Terrestrial Extremes; 1988:153-226.

5. Aoyagi Y, McLellan TM, Shephard RJ. Effects of training and acclimation on heat tolerance in exercising men wearing protective clothing. Eur J Appl Physiol Occup Physiol. 1994;68:234-245.

6. Nielsen B. Olympics in Atlanta: a fight against physics. Med Sci Sports Exerc. 1996;28:665-668.

7. Shapiro Y, Moran D, Epstein Y. Acclimatization strategies-preparing for exercise in the heat. Int J Sports Med. 1998;19(Suppl 2):S161-S163.

8. Wade CE, Veghte JH. Thermographic evaluation of the relative heat loss by area in man after swimming. Aviat Space Environ Med. 1977;48:16-18.

9. Holmér I, Bergh U. Metabolic and thermal response to swimming in water at varying temperatures. J Appl Physiol. 1974;37:702-705.

10. Hue $\mathrm{O}$, Galy $\mathrm{O}$. The effect of a silicone swim cap on swimming performance in tropical conditions in pre-adolescents. J Sports Sci Med. 2012, in press.

11. Kerr CG, Trappe TA, Starling RD, Trappe SW. Hyperthermia during Olympic triathlon: influence of body heat storage during the swimming stage. Med Sci Sports Exerc. 1998;30:99-104.

12. Peeling P, Landers G. The effect of a one-piece competition speedsuit on swimming performance and thermoregulation during a swim-cycle trial in triathletes. J Sci Med Sport. 2007;10:327-333.

13. Nybo L. Cycling in the heat: performance perspectives and cerebral challenges. Scand J Med Sci Sports. 2010;20:71-79.

14. Sheffield-Moore M, Short KR, Kerr CG, Parcell AC, Bolster DR, Costill DL. Thermoregulatory responses to cycling with and without a helmet. Med Sci Sports Exerc. 1997;29:755-761.

15. Saunders AG, Dugas JP, Tucker R, et al. The effects of different air velocities on heat storage and body temperature in humans cycling in a hot, humid environment. Acta Physiol Scand. 2005;183:241-255.

16. Hue O, Voltaire B, Hertogh C, Blonc S. Heart rate, thermoregulatory and humoral responses during a 9-day cycle race in a hot and humid climate. Int J Sports Med. 2006;27:690-696.

17. Lucía A, Hoyos J, Santalla A, Earnest C, Chicharro JL. Tour de France versus Vuelta a Espana : which is harder. Med Sci Sports Exerc. 2003;35:872-878.

18. Kenefick RW, Cheuvront SN, Sawka MN. Thermoregulatory function during the marathon. Sports Med. 2007;37:312-315. 
19. Ely MR, Cheuvront SN, Roberts WO, Montain SJ. Impact of weather on marathonrunning performance. Med Sci Sports Exerc. 2007;39:487-493.

20 Dennis SC, Noakes TD. Advantages of a smaller bodymass in humans when distancerunning in warm, humid conditions. Eur J Appl Physiol Occup Physiol. 1999;79:280-284.

21. Marino FE, Mbambo Z, Kortekaas E, et al. Advantages of smaller body mass during distance running in warm, humid environments. Pflugers Arch. 2000;441:359-367.

22. Armstrong LE, Maresh CM. The induction and decay of heat acclimatisation in trained athletes. Sports Med. 1991;12:302-312.

23. Hue O, Voltaire B, Galy O, et al. Effects of 8 days acclimation on biological and performance response in a tropical climate. J Sports Med Phys Fitness. 2004;44:30-37.

24. Voltaire B, Galy O, Coste O, et al. Effect of fourteen days of acclimatization on athletic performance in tropical climate. Can J Appl Physiol. 2002;27:551-562.

25. Bae JS, Lee JB, Matsumoto T, et al. Prolonged residence of temperate natives in the tropics produces a suppression of sweating. Pflugers Arch. 2006;453:67-72.

26. Saat M, Sirisinghe RG, Singh R, Tochihara Y. Effects of short-term exercise in the heat on thermoregulation, blood parameters, sweat secretion and sweat composition of tropic-dwelling subjects. J Physiol Anthropol Appl Human Sci. 2005;24:541-549.

27. Voltaire B, Berthouze-Aranda S, Hue O. Influence of a hot/wet environment on exercise performance in natives to tropical climate. J Sports Med Phys Fitness. 2003;43:306-311.

28. Lorenzo S, Halliwil JR, Sawka MN, Minson CT. Heat acclimation improves exercise performance. J Appl Physiol. 2010;109:1140-1147.

29. Wright A, Marino FE, Kay D, et al. Influence of lean body mass on performance differences of male and female distance runners in warm, humid environments. Am J Phys Anthropol. 2002;118:285-291.

30. Kuwahara T, Inoue Y, Abe M, Sato Y, Kondo N. Effects of menstrual cycle and physical training on heat loss responses during dynamic exercise at moderate intensity in a temperate environment. Am J Physiol Regul Integr Comp Physiol. 2005;288:R1347-R1353.

31. Nybo L, Jensen T, Nielsen B, González-Alonso J. Effects of marked hyperthermia with and without dehydration on $\mathrm{VO}(2)$ kinetics during intense exercise. J Appl Physiol. 2001;90:1057-1064.

32. Chu AL, Jay O, White MD. The effects of hyperthermia and hypoxia on ventilation during low-intensity steady-state exercise. Am J Physiol Regul Integr Comp Physiol. 2007;292:R195-R203.

33. Hue O, Antoine-Jonville S, Galy O, Blonc S. Maximal oxygen uptake, ventilatory thresholds and mechanical power during cycling in Tropical climate in Guadeloupean elite cyclists. J Sci Med Sport. 2010;13:607-612.

34. Racinais S. Differents effects of heat exposure upon exercise performance in the morning and afternoon. Scand J Med Sports. 2010;20:80-89.

35. Hobson RM, Clapp EL, Watson P, Maughan RJ. Exercise capacity in the heat is greater in the morning than in the evening in man. Med Sci Sports Exerc. 2009;41:174-180.

36. Sawka MN, Noakes TD. Does dehydration impair exercise performance? Med Sci Sports Exerc. 2007;39:1209-1217.

37. Brun JF, Khaled S, Raynaud E, et al. The triphasic effects of exercise on blood rheology: which relevance to physiology and pathophysiology? Clin Hemorheol Microcirc. 1998;19:89-104.

38. Gleeson M. Temperature regulation during exercise. Int J Sports Med. 1998;19(Suppl 2):S96-S99.

39. Hue O, Antoine-Jonville S, Sara F. The effect of 8 days of training in tropical environment on performance in neutral climate in swimmers. Int J Sports Med. 2007;28:48-52.

40. Honma K, Honma S, Kohsaka M, Fukuda N. Seasonal variation in the human circadian rhythm: dissociation between sleep and temperature rhythm. Am J Physiol. 1992;262:R885-R891.

41. Fujita M, Lee D, Ismail MS, Tochihara Y. Seasonal effects of sleep deprivation on thermoregulatory responses in a hot environment. J Physiol Anthropol Appl Human Sci. 2003;22:273-278. 